\title{
How Predictable Are the Arctic and North Atlantic Oscillations? Exploring the Variability and Predictability of the Northern Hemisphere
}

\author{
DANIELA I. V. DOMEISEN ${ }^{\mathrm{a}}$ \\ GEOMAR Helmholtz Centre for Ocean Research Kiel, and Christian-Albrechts University of Kiel, Kiel, Germany \\ GUALTIERO BADIN \\ Institute of Oceanography, Center for Earth System Research and Sustainability (CEN), University of \\ Hamburg, Hamburg, Germany \\ INGA M. KOSZALKA \\ GEOMAR Helmholtz Centre for Ocean Research Kiel, and Christian-Albrechts University of Kiel, Kiel, Germany
}

(Manuscript received 11 April 2017, in final form 11 August 2017)

\begin{abstract}
The North Atlantic Oscillation (NAO) and the Arctic Oscillation (AO) describe the dominant part of the variability in the Northern Hemisphere extratropical troposphere. Because of the strong connection of these patterns with surface climate, recent years have shown an increased interest and an increasing skill in forecasting them. However, it is unclear what the intrinsic limits of short-term predictability for the NAO and AO patterns are. This study compares the variability and predictability of both patterns, using a range of data and index computation methods for the daily NAO and AO indices. Small deviations from Gaussianity are found along with characteristic decorrelation time scales of around one week. In the analysis of the Lyapunov spectrum it is found that predictability is not significantly different between the AO and NAO or between reanalysis products. Differences exist, however, between the indices based on EOF analysis, which exhibit predictability time scales around 12-16 days, and the station-based indices, exhibiting a longer predictability of 18-20 days. Both of these time scales indicate predictability beyond that currently obtained in ensemble prediction models for short-term predictability. Additional longer-term predictability for these patterns may be gained through local feedbacks and remote forcing mechanisms for particular atmospheric conditions.
\end{abstract}

\section{Introduction}

The North Atlantic Oscillation (NAO) and the Arctic Oscillation $(\mathrm{AO})$ are spatiotemporal patterns of airmass variability in the North Atlantic region and the extratropical Northern Hemisphere, respectively (Hurrell 1995; Greatbatch 2000; Hurrell et al. 2001; Visbeck et al. 2001). The NAO and AO patterns dominate the variability of the atmosphere on time scales of days to decades (Thompson and Wallace 2000; Thompson et al. 2000; Woollings et al. 2015). They arise as a signal of internal atmospheric variability (i.e., through the

\footnotetext{
${ }^{\text {a }}$ Current affiliation: Institute for Atmospheric and Climate Science, ETH Zurich, Zurich, Switzerland.

Corresponding author: Daniela Domeisen, daniela.domeisen@ env.ethz.ch
}

interaction between eddies and the mean flow; DeWeaver and Nigam 2000; Barnes and Hartmann 2010) and as a response to external forcing from, for example, the stratosphere (Baldwin and Dunkerton 1999, 2001; Black 2002; Kidston et al. 2015), the ocean (Visbeck 2002; Gastineau and Frankignoul 2015; Gulev and Latif 2015), and sea ice (Krahmann and Visbeck 2003; Semenov and Latif 2015). In turn, the NAO exerts a forcing on the interannual and decadal variability of the ocean circulation (Eden and Jung 2001; Badin et al. 2003; Mecking et al. 2015; Delworth et al. 2017).

The NAO governs the major weather patterns over the North Atlantic, North America, and Europe (Thompson and Wallace 2000; Visbeck et al. 2001). A negative phase of the NAO is associated with a large arching pattern of the jet stream over the North Atlantic and a southward-shifted storm track over Europe, 
leading to colder and drier than average weather in northern Europe and wetter conditions in southern Europe. A positive phase of the NAO is associated with an anomalous strength of the semistationary Icelandic low and Azores high pressure regions, favoring a more zonal jet stream over the North Atlantic and a northward shift of the storm track over Europe, bringing wetter and warmer weather to northern Europe and dry weather to southern Europe (Visbeck et al. 2001; Hurrell et al. 2001). The AO instead pertains to the full longitudinal and latitudinal range and is closely related to the northern annular mode (NAM; Thompson and Wallace 2000; Gerber et al. 2008a,b). AO variability is dominated by the variation in strength of the Icelandic low and the Aleutian low, which are in turn related to the NAO and the Pacific-North American (PNA) pattern, respectively (Thompson and Wallace 1998).

Because of their success as a low-dimensional description of interactions between the ocean and the atmosphere for seasonal-to-multiannual variability (Rodwell and Folland 2002; Woollings et al. 2015), the NAO and AO patterns have been a focus of the atmospheric community for the past few decades. Still, in view of the increased efforts to predict weather phenomena benefiting the understanding of societal impacts, questions remain regarding the definition of the NAO and $\mathrm{AO}$ indices and their predictability.

\section{a. $N A O$ and $A O$ index definition}

The NAO and AO are usually defined in terms of surface pressure (e.g., Hurrell et al. 2001) or geopotential height on a pressure level, usually 500 or $1000 \mathrm{hPa}$ (e.g., Kunz and Greatbatch 2013). Traditionally, the NAO has been defined as the pressure difference between meteorological stations in Iceland and the Azores (Thompson and Wallace 2000), here called the station-based index. One such index is used in this study (Cropper et al. 2015). Other NAO definitions focus on large-scale spatiotemporal variability and employ an empirical orthogonal function (EOF) analysis of geopotential height or sea level pressure over the North Atlantic (Thompson and Wallace 2000; Hurrell et al. 2001), where the first principal component (PC1) time series serves as the NAO index. The AO is most often defined as the dominant EOF over the extratropical Northern Hemisphere, with the PC1 time series as the AO index. The advantage of EOF analysis is the reduction of the dimensionality of the spatiotemporal variability, as the first PC corresponds to the spatial pattern explaining the most variance. The EOF-based definition, however, implies orthogonalization and hence linearization, at the cost of a (possible) loss of information about the nonlinearity, smaller-scale variability and its time evolution. In addition, the values of the EOF-based indices may change slightly for including a longer or updated dataset. On the other hand, station-based indices lack the possibility to track the movement of the centers of action with the seasonal cycle, as will be addressed further in this study. Several different versions of the indices based on EOF analysis exist (Baldwin and Thompson 2009), including regression on surface pressure or other atmospheric variables (Kunz and Greatbatch 2013), rotated principal component analysis, and/or projection and truncation procedures in order to remove noise (e.g., Barnston and Livezey 1987). The question remains how the differences arising from the NAO and AO index definitions and the different available datasets may lead to differences in the variability and predictability of these indices.

\section{b. NAO and $A O$ predictability}

Because of the close link between the variability of $\mathrm{NAO} / \mathrm{AO}$ indices and extratropical weather, the skillful prediction of these indices has become an important topic in research and in operational prediction, both for the NAO (e.g., Scaife et al. 2014) and the AO (Stockdale et al. 2015). While the weather over Europe tends to be particularly difficult to predict past time scales of about one week (Kolstad et al. 2015), recent advances have indicated that the influence of several teleconnections may significantly extend the predictability of the NAO (and possibly also the AO) on a variety of time scales. Recent studies point to significantly increased skill in dynamical forecast models on seasonal (Scaife et al. 2014) to annual time scales (Dunstone et al. 2016), as well as in statistical models (Hall et al. 2017). Candidates for external forcings are tropical variability in terms of El Niño-Southern Oscillation (ENSO) in the tropical Pacific (Brönnimann 2007; Scaife et al. 2014; Domeisen et al. 2015; Richter et al. 2015; Butler et al. 2016) and the Madden-Julian oscillation (MJO), a zonally propagating band of convective rainfall at the equator (Cassou 2008; Garfinkel et al. 2014), in addition to the stratosphere (Baldwin and Dunkerton 2001; Scaife et al. 2005; Stockdale et al. 2015), Arctic sea ice (Deser et al. 2000; Petoukhov and Semenov 2010; Gao et al. 2015; Sun et al. 2015), and solar variability (Thiéblemont et al. 2015).

In the abovementioned studies, ensemble simulations are used to assess the skill of prediction systems using weather or climate prediction models. While numerical models provide a valuable indication of the inherent predictability of weather and climate indices, it has recently been suggested that they may underestimate the predictability present in observations (Eade et al. 2014). It is therefore important to gain a sense of the day-today predictability inherent to the time series themselves. One approach to estimate the inherent predictability 
TABLE 1. Overview of the time series used in this study for the AO (top) and the NAO (bottom).

\begin{tabular}{llc}
\hline \multicolumn{1}{c}{ Name } & \multicolumn{1}{c}{ Method } & Data source \\
\hline AO & PC1 of 1000-hPa geopotential height anomaly & NCEP-1 \\
PC CPC & PC1 of 500-hPa geopotential height anomaly & ERA-Interim, proprietary \\
PC ERA-Interim & PC1 of 500-hPa geopotential height anomaly & ERA-40, proprietary \\
PC ERA-40 & PC1 of 500-hPa geopotential height anomaly & NCEP-1, proprietary \\
PC NCEP-1 & PC1 of 500-hPa geopotential height anomaly & NCEP-2, proprietary \\
PC NCEP-2 & & \\
NAO & Station based & Various \\
Cropper et al. (2015) & Station based (Reykjavik and Ponta Delgada) \\
ERAi-RPD & Station based (Reykjavik, Ponta Delgada, and Lisbon) & ERA-Interim, proprietary \\
ERAi-RPDL & PC1 of 500-hPa geopotential height anomaly & ERA-Interim, proprietary \\
PC CPC & PC1 of 500-hPa geopotential height anomaly & NCEP-1 \\
PC ERA-Interim & PC1 of 500-hPa geopotential height anomaly & ERA-Interim, proprietary \\
PC ERA-40 & PC1 of 500-hPa geopotential height anomaly & ERA-40, proprietary \\
PC NCEP-1 & PC1 of 500-hPa geopotential height anomaly & NCEP-1, proprietary \\
PC NCEP-2 & & NCEP-2, proprietary \\
\hline
\end{tabular}

on a day-to-day basis is based on dynamical systems theory and consists of the computation of the Lyapunov exponents, which quantify the growth rate of perturbations in the reconstructed phase space of the system. The inverse of the Lyapunov exponents can thus be interpreted as an intrinsic time scale of the predictability of day-to-day variations. This method has been employed previously in the context of stratospheric variability by Badin and Domeisen (2014a,b). Note that the Lyapunov analysis gives an estimate of the short-term predictability, while the abovementioned remote forcing mechanisms may be able to further affect or extend predictable lead times for particular atmospheric conditions beyond the time scales indicated by the Lyapunov analysis.

\section{c. Goals of this study}

The aim of this work is to address the following two questions: 1) What is the intrinsic time scale of day-today predictability for the NAO and AO in terms of the Lyapunov exponents? 2) To what extent do the differing NAO and AO index definitions and datasets lead to changes in variability and predictability?

To this end, we evaluate publicly available index time series of the NAO and the AO with at least daily resolution and compare them to time series derived proprietarily using EOF analysis and to station-based indices for the NAO. We show how differences in spatial resolution of the datasets and different index definitions imprint on variability expressed in common statistics and time series analysis tools. In addition, as a novel aspect for NAO and AO variability, we use Lyapunov exponents to quantify the predictability for the AO and NAO index time series.

Section 2 presents the data and the methods used to compute the AO and NAO index time series. Section 3 introduces the statistics and data analysis tools used to quantify variability and provides the theoretical background on Lyapunov spectra and how they can be used to assess predictability. The results regarding the AO and NAO variability and predictability are given in section 4 . Section 5 provides a discussion of the results in terms of the different datasets and index definitions and the predictability measure employed.

\section{Data sources and index definitions}

In this section we describe the procedure used to calculate the daily EOF-based indices as well as the sources for the station-based and community versions of the NAO and the AO. Table 1 gives a list of the time series used for the analysis, and Fig. 1 shows excerpts from the resulting index time series.

\section{a. EOF-based indices}

Daily mean values from the following reanalysis datasets are used: ERA-Interim (Dee et al. 2011), ERA-40 (Uppala et al. 2005), NCEP-NCAR reanalysis (NCEP-1; Kalnay et al. 1996); and NCEP-DOE AMIP-II reanalysis (NCEP-2; Kanamitsu et al. 2002). For this study, all time series have been limited to the common time period 1 January 1979-31 December 2001 (23 yr), yielding a total of 8401 daily data points for each time series. The ECMWF and NCEP reanalysis families have a native spatial resolution of $0.75^{\circ}$ and $2.5^{\circ}$ in latitude/longitude, respectively.

The proprietary EOF-based NAO and AO indices are computed from 500-hPa geopotential height by limiting the area to $20^{\circ}-90^{\circ} \mathrm{N}$ and additionally to $90^{\circ} \mathrm{W}-40^{\circ} \mathrm{E}$ for the NAO, while for the AO the entire longitude range is used. The data are weighted by the square root of the 
(100

${ }_{100}$
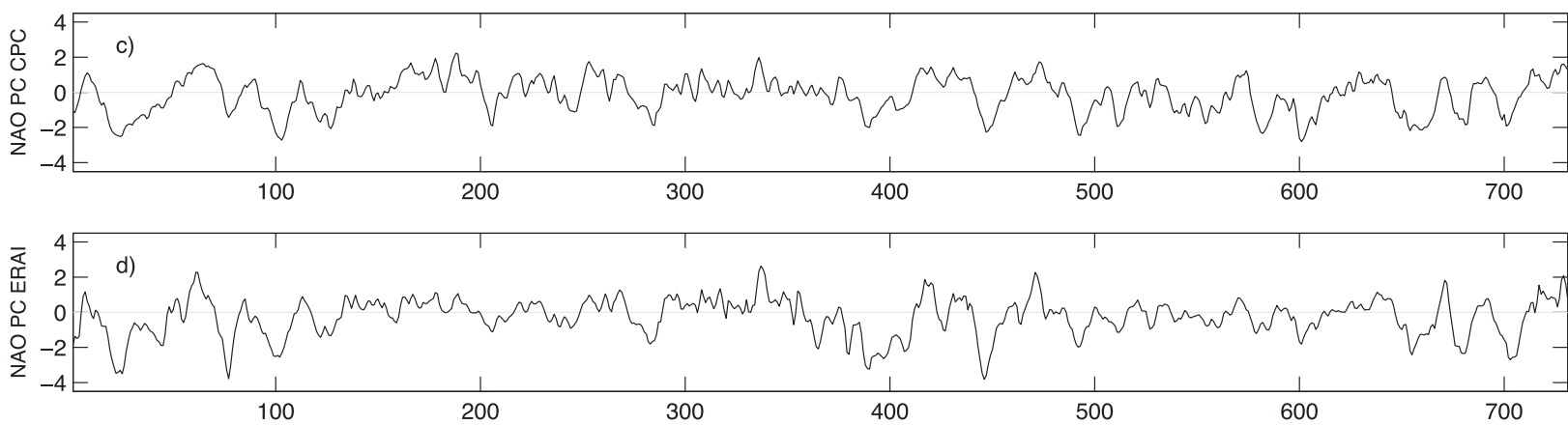

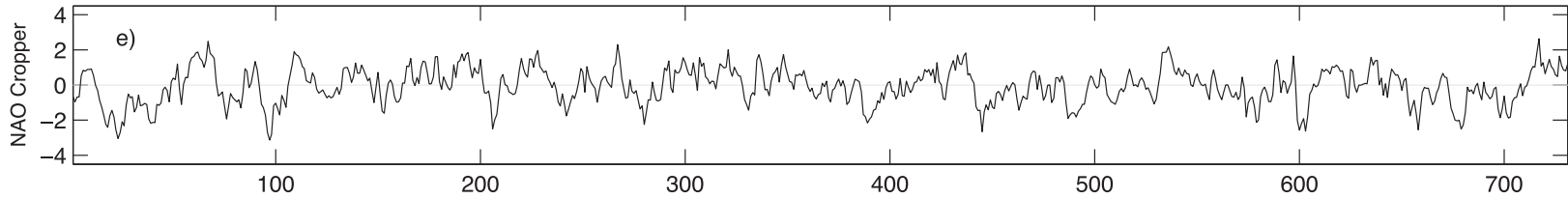

$\underset{100}{\frac{1}{2}}$

FIG. 1. Daily index time series of the (a),(b) AO and (c)-(f) NAO for 1 Jan 1979-31 Dec 1980. The time series for CPC are shown in (a),(c), and the proprietary time series for ERA-Interim are shown in (b),(d). The NAO time series for the station-based Cropper et al. (2015) time series is shown in (e), and the proprietary station-based NAO time series ERAi-RPDL is shown in (f) (see text for description).

cosine of latitude to account for the decreasing area toward the pole. The daily seasonal cycle climatology computed for the entire time period has been subtracted for each grid point. As a standard procedure for the EOF analysis, from each dataset, a linear trend is removed at every grid point. A singular value decomposition has been used to generate the EOF spatial patterns and the corresponding PC time series. The PC corresponding to the EOF pattern explaining the most variance is defined as the NAO or AO index, respectively. The variance explained by the proprietary EOF patterns is shown in the first column of Table 2. Note that the variance explained is about twice as large for the NAO $(15 \%-16 \%)$ as compared to the $\mathrm{AO}(\sim 7.5 \%)$. This is likely related to a dominant weight of the AO in the North Atlantic.

\section{b. Community $N A O$ and $A O$ indices}

In addition to the proprietary computation of the $\mathrm{NAO}$ and $\mathrm{AO}$ indices from reanalysis data, additional publicly available NAO and AO indices have been used: the EOF-based indices from the Climate Prediction Center (CPC) computed from NCEP-1 (Kalnay et al. 1996) have been used for both the NAO and the AO. The leading AO pattern from CPC is computed from an EOF analysis applied to the deseasonalized monthly mean $1000-\mathrm{hPa}$ height anomalies poleward of $20^{\circ} \mathrm{N}$ from NCEP-1, weighted by the square root of the cosine of latitude. Daily and monthly AO indices are then computed by projecting the daily and monthly mean $1000-\mathrm{hPa}$ height anomalies onto, and normalized with respect to, 
TABLE 2. Basic properties of the time series and probability density distributions: the variance explained by the EOF analysis (the asterisk denotes a slightly different computation period, i.e., 1979-2000), the maximum and minimum values of the time series, the skewness and the kurtosis (deviation from the value of 3 for a normalized Gaussian distribution), and the correlation coefficient with the station-based Cropper et al. (2015) NAO time series.

\begin{tabular}{|c|c|c|c|c|c|c|}
\hline & Variance explained & Max & Min & Skewness & Kurtosis minus 3.0 & Corr(Cropper) \\
\hline \multicolumn{7}{|l|}{$\mathrm{AO}$} \\
\hline PC CPC & $19 \% *$ & 4.11 & -4.32 & $0.04 \pm 0.29$ & $0.64 \pm 0.59$ & 0.55 \\
\hline PC ERA-Interim & $7.3 \%$ & 3.61 & -4.21 & $-0.21 \pm 0.15$ & $0.50 \pm 0.29$ & 0.58 \\
\hline PC ERA-40 & $7.4 \%$ & 3.61 & -4.23 & $-0.20 \pm 0.15$ & $0.51 \pm 0.30$ & 0.58 \\
\hline PC NCEP-1 & $7.6 \%$ & 3.62 & -4.28 & $-0.23 \pm 0.15$ & $0.51 \pm 0.29$ & 0.60 \\
\hline PC NCEP-2 & $7.6 \%$ & 3.66 & -4.30 & $-0.23 \pm 0.14$ & $0.51 \pm 0.29$ & 0.60 \\
\hline \multicolumn{7}{|l|}{ NAO } \\
\hline Cropper et al. (2015) & - & 3.21 & -3.86 & $-0.24 \pm 0.14$ & $-0.11 \pm 0.28$ & 1.00 \\
\hline ERAi-RPD & - & 3.35 & -4.71 & $-0.30 \pm 0.15$ & $0.68 \pm 0.31$ & 0.91 \\
\hline ERAi-RPDL & - & 3.74 & -4.59 & $-0.36 \pm 0.18$ & $0.91 \pm 0.36$ & 0.83 \\
\hline PC CPC & - & 2.81 & -3.42 & $-0.18 \pm 0.20$ & $-0.19 \pm 0.40$ & 0.56 \\
\hline PC ERAint & $15.6 \%$ & 3.22 & -3.81 & $-0.31 \pm 0.20$ & $0.43 \pm 0.40$ & 0.66 \\
\hline PC ERA-40 & $15.7 \%$ & 3.24 & -3.86 & $-0.31 \pm 0.20$ & $0.44 \pm 0.40$ & 0.66 \\
\hline PC NCEP-1 & $16.1 \%$ & 3.12 & -3.83 & $-0.32 \pm 0.20$ & $0.47 \pm 0.40$ & 0.67 \\
\hline PC NCEP-2 & $16.0 \%$ & 3.11 & -3.85 & $-0.33 \pm 0.20$ & $0.47 \pm 0.40$ & 0.67 \\
\hline
\end{tabular}

the leading monthly mode. The NAO index is computed using rotated principal component analysis on monthly standardized $500-\mathrm{hPa}$ geopotential height anomalies in the region $20^{\circ}-90^{\circ} \mathrm{N}$. The monthly time series are then linearly interpolated to the day in question. More information is available on the project web page (http://www.cpc.ncep.noaa.gov/products/precip/ CWlink/daily_ao_index/history/method.shtml) and in Barnston and Livezey (1987).

\section{c. Station-based indices}

For the NAO, in addition a station-based time series was available (Cropper et al. 2015), based on a reconstruction of daily station-based data starting in 1850. The reconstruction uses daily sea level pressure observations from several stations in Iceland and the Azores. The stations' time series are corrected for altitudinal differences and the gaps are filled and homogenized with reanalysis data from the Twentieth Century Reanalysis project (Compo et al. 2011) and European mean sea level pressure (Ansell et al. 2006).

To better understand predictability from station-based indices, we also generate a proprietary station-based NAO index by linearly interpolating the ERA-Interim mean sea level pressure (MSLP) at the reference stations of Reykjavik, Iceland, and Ponta Delgada, Portugal, the most relevant reference stations for the period 1979-2001 for the composite indices generated by Cropper et al. (2015) [see also Jones et al. (1997)]. We call this index ERAi-RPD. The interpolation method (linear, nearest neighbor, spline) has no discernible effect on the index.
To address the effect of the seasonal cycle on the centers of action for the station-based index, we generate another proprietary station-based index by replacing the Punta Delgada time series with the MSLP time series from Lisbon, Portugal, [the more relevant winter location according to Hurrell (1995)] in the DecemberMarch period of each year. We call the time series of this station-based index ERAi-RPDL.

To render the large variety of different index time series comparable, the sign of the PC was reversed for the proprietary time series computed from ERA-40 and ERA-Interim data to match the sign of the time series from NCEP, CPC, and the station-based indices. Finally, all index time series are normalized by removing their respective means and dividing by the standard deviations computed over the full analysis period.

Neither the CPC indices nor any of the station-based indices [i.e., the Cropper et al. (2015) index or the proprietary station-based indices derived from reanalysis] show evidence of linear trends. The least squares fits yield trend estimates that explain less than $0.25 \%$ of the variance and are insignificant under the Student's $t$ test with the degrees of freedom scaled by the decorrelation time scale $\tau_{E}$ (in Table 3 ) for each of these indices.

\section{Methods}

\section{a. Statistical and spectral analysis}

To assess how different datasets and index definitions reflect on the variability, we use common statistics (distributions and moments) as well as characteristic time scales derived from autocorrelation functions and 
TABLE 3. Autocorrelation and predictability measures for the AO and NAO: the exponential decay time scale $\tau_{E}$ (days), the zero-crossing decay time $\tau_{\mathrm{ZC}}$ (days), the integral decorrelation time scales $\tau_{I}$ (days) given as the mean over the first 30-60 days of the autocorrelation function (first value) and the mean over the last 185 days (second value; an em dash indicates that no convergence is reached), the sum of the Lyapunov exponents $\Sigma_{i} \lambda_{i}\left(\right.$ day $\left.^{-1}\right)$, the inverse of the sum of all positive Lyapunov exponents (day), the inverse of the largest positive Lyapunov exponent (day), and the Kaplan-Yorke dimension $D_{\mathrm{KY}}$ (dimensionless).

\begin{tabular}{|c|c|c|c|c|c|c|c|}
\hline & $\tau_{E}$ & $\tau_{\mathrm{ZC}}$ & $\tau_{I}$ & $\Sigma_{i} \lambda_{i}$ & $1 / \lambda_{+}$ & $1 / \lambda_{\max }$ & $D_{\mathrm{KY}}$ \\
\hline \multicolumn{8}{|l|}{$\mathrm{AO}$} \\
\hline PC CPC & 9 & 121 & $-/ 28$ & $-0.85 \pm 0.02$ & $12 \pm 1$ & $16.9 \pm 0.5$ & $4.03 \pm 0.02$ \\
\hline PC ERA-Interim & 7 & 30 & $7 / 23$ & $-0.87 \pm 0.03$ & $12 \pm 1$ & $16.6 \pm 0.4$ & $3.99 \pm 0.08$ \\
\hline PC ERA-40 & 7 & 32 & $7 / 25$ & $-0.88 \pm 0.02$ & $12 \pm 2$ & $17.0 \pm 0.5$ & $3.98 \pm 0.09$ \\
\hline PC NCEP-1 & 7 & 30 & $7 / 22$ & $-0.80 \pm 0.02$ & $11 \pm 1$ & $16.1 \pm 0.5$ & $4.16 \pm 0.06$ \\
\hline PC NCEP-2 & 7 & 29 & $7 / 20$ & $-0.80 \pm 0.02$ & $11 \pm 1$ & $16.0 \pm 0.6$ & $4.17 \pm 0.05$ \\
\hline \multicolumn{8}{|l|}{ NAO } \\
\hline Cropper et al. (2015) & 5 & 28 & $5 /-$ & $-2.36 \pm 0.03$ & $20 \pm 2$ & $20.0 \pm 2.0$ & $2.50 \pm 0.05$ \\
\hline ERAi-RPD & 6 & 33 & $6 /-$ & $-2.34 \pm 0.04$ & $20 \pm 2$ & $20.0 \pm 2.0$ & $2.50 \pm 0.10$ \\
\hline ERAi-RPDL & 5 & 46 & $6 /-$ & $-2.29 \pm 0.06$ & $18 \pm 2$ & $18.0 \pm 2.0$ & $2.80 \pm 0.20$ \\
\hline PC CPC & 7 & 56 & $8 / 10$ & $-0.79 \pm 0.03$ & $12 \pm 2$ & $16.2 \pm 0.8$ & $4.13 \pm 0.07$ \\
\hline PC ERA-Interim & 6 & 56 & $7 / 20$ & $-0.99 \pm 0.04$ & $13 \pm 2$ & $18.0 \pm 1.0$ & $3.70 \pm 0.10$ \\
\hline PC ERA-40 & 6 & 56 & $7 / 21$ & $-0.99 \pm 0.04$ & $13 \pm 5$ & $17.6 \pm 0.9$ & $3.70 \pm 0.20$ \\
\hline PC NCEP-1 & 6 & 55 & $7 / 21$ & $-0.88 \pm 0.03$ & $12 \pm 2$ & $16.6 \pm 0.4$ & $4.00 \pm 0.08$ \\
\hline PC NCEP-2 & 6 & 55 & $7 / 19$ & $-0.89 \pm 0.03$ & $12 \pm 2$ & $16.2 \pm 0.6$ & $4.00 \pm 0.10$ \\
\hline
\end{tabular}

spectral analysis. We use four different measures of the decorrelation time scale: 1) $\tau_{E}$, the time when the timelagged autocorrelation function of a time series crosses the value of $e^{-1}$ (i.e., the decorrelation time scale; e.g., Baldwin et al. 2003; Gerber et al. 2008a);2) $\tau_{\mathrm{ZC}}$, the time when the autocorrelation function crosses zero; and 3 ) the first minimum of the mutual information (Fraser and Swinney 1986), which yields comparable results to $\tau_{\text {ZC. }}$. We also compute 4) the integral time scale derived from the autocorrelation function $\tau_{I}=\lim _{\tau \rightarrow \infty} \int R(\tau) d \tau$, where $R$ is the autocorrelation function, $\tau$ is the time lag, and the limit refers to a period of convergence. This quantity has been used previously to relate the Eulerian and Lagrangian time scales and the related length scales of large-scale planetary turbulence (Panchev 2016). Unlike $\tau_{E}$ and $\tau_{\mathrm{ZC}}$, it also allows for an investigation of the long-time-scale behavior of the time series, as further discussed in section $4 \mathrm{c}$. The frequency spectra were computed using the fast Fourier transform (FFT) method without windowing or spectral averaging and with zero padding.

\section{b. Lyapunov exponents as a measure of predictability}

This section gives a brief introduction to using Lyapunov exponents as a measure of predictability. For a more detailed description see, for example, Badin and Domeisen (2014a,b) and references therein.

The spectrum of Lyapunov exponents is here calculated following the algorithm of Sano and Sawada (1985), which is based on the embedding theorem by Whitney (1936) and Takens (1981). Following this theorem, a time series $x(t)$ spans a phase space that can be embedded in an $M$-dimensional space defined by the delay coordinates:

$$
\mathbf{x}(t)=\{x(t), x(t+\tau), \ldots, x[t+(M-1) \tau]\},
$$

here $\tau$ is a time lag, also called delay time. For the maximum embedding dimension, the definition by Ruelle (1990), given as

$$
M=2 \log _{10} N,
$$

is used, where $N$ is the number of data points in the time series. The dynamics will lie on a strange attractor with (fractal) dimension $D<M$. For all AO and NAO time series in this study, a maximum embedding dimension of $M=8$ has been used and the convergence of the results has been tested for different values of $M$.

As a preparation for the computation of the Lyapunov spectrum, the time series have to first be split into periods of a suitable length (i.e., the delay time $\tau$ ). Each period is assumed to contain the necessary information and typical behavior of the time series. For the computation of the Lyapunov exponents $\tau=\tau_{\mathrm{ZC}}$ is used. To obtain an estimate of the sensitivity to variations in the delay time, the calculations were repeated for the values of $\tau-2, \tau-1$, $\tau+1$, and $\tau+2$. The results are reported as the mean and standard deviation of this ensemble of calculations. Additional sensitivity tests were performed using the first minimum of the mutual information, leading to comparable results within error bars. The decorrelation time scale $\tau_{E}$ was however found to be too short for the convergence of the results and was thus not used. 
The Lyapunov spectrum $\lambda_{1} \geq \ldots \geq \lambda_{M}$ is computed from the estimation of the rate of separation of the trajectories in the reconstructed phase space. For chaotic systems, the Lyapunov spectrum is characterized by at least one positive Lyapunov exponent, indicating an exponential separation of the trajectories and sensitivity to initial conditions. For stochastic systems, a positive Lyapunov exponent indicates the rate of separation between realizations of the system. In this sense, the inverse of the Lyapunov exponents are a natural measure for the predictability time scale of the system in question. Note, however, that a system may be characterized by more than one positive Lyapunov exponent. An important quantity for predictability is thus the sum of the positive Lyapunov exponents:

$$
\lambda_{+}=\sum_{i=1}^{j} \lambda_{i},
$$

where the index $j$ is defined such that $\lambda_{1} \geq \ldots \geq \lambda_{j}>0$. The quantity in (1) is an upper bound for the Kolmogorov-Sinai entropy (Pesin 1976) and thus for the loss of predictability of the system. In addition, $\lambda_{+}$can be used to estimate the dimension of the attractor in phase space where the dynamics take place, that is, the Kaplan-Yorke (KY) dimension (Kaplan and Yorke 1979):

$$
D_{\mathrm{KY}}=j+\frac{\lambda_{+}}{\left|\lambda_{j+1}\right|} .
$$

Qualitatively, $D_{\mathrm{KY}}$ can be seen as a measure of complexity of the system. A system with a larger value of $D_{\mathrm{KY}}$ will require a longer time series for the exploration of the entire phase space and to eventually ensure ergodicity. The convergence of $D_{\mathrm{KY}}$ to a low value $\left(D_{\mathrm{KY}}<M\right)$ will instead ensure full coverage of the strange attractor of the system. Finally, note that dissipative systems are characterized by a contraction of phase space and thus by a negative value of the sum of all Lyapunov exponents.

\section{Results}

We here present the NAO and AO index time series and the analysis of their variability and predictability-that is, the statistical moments and probability distributions as well as frequency spectra quantifying the degree of departure from Gaussianity, the linear and nonlinear decorrelation time scales, and the predictability measures by means of Lyapunov exponents.

\section{a. The NAO and $A O$ index time series}

Figure 1 gives several examples of the NAO and AO index time series used in this study for the time period 1 January 1979-31 December 1980. As the proprietary EOF-based time series are visually indistinguishable for the different reanalysis datasets (ERA-Interim, ERA-40, NCEP-1, and NCEP-2), ERA-Interim is chosen to represent the other reanalyses (Figs. 1b,d). The AO and NAO time series show a similar variability, indicating that the AO time series may be dominated by North Atlantic variability.

While the CPC and proprietary EOF-based indices show a similar variability, the most striking difference can be observed between the EOF-based indices and the station-based NAO indices, which show more pronounced high-frequency variability. This difference arises as a result of either the use of localized observation sites or the contribution of additional linear or nonlinear modes of variability that are filtered out when using EOF-based indices.

The last column in Table 2 indicates the correlation coefficient between the station-based Cropper et al. (2015) NAO time series and the other datasets. As expected, the NAO time series are generally more strongly correlated with the Cropper NAO index. Among the EOF-based indices, the strongest correlation with Cropper is observed for the NAO PC NCEP-2 time series. Although, interestingly, the NAO indices exhibit correlations with Cropper that are only marginally stronger than for the AO time series.

\section{b. Distributions and central moments}

The probability density functions (PDFs) for the NAO and AO normalized by the standard deviation are shown in Fig. 2. Table 2 gives the basic properties for all time series. Because of the normalization, all time series exhibit zero mean and a standard deviation of 1 . The comparison to a Gaussian distribution is here given by the skewness as a measure of the symmetry of the data about their mean and the kurtosis as a measure of the tails of the data in the probability distribution (reported as the deviation from the kurtosis value of 3 for a normalized Gaussian distribution).

All proprietary EOF-based time series show a closely aligned negative skewness (from -0.21 to -0.33 ), and ERA-Interim is therefore chosen to represent the PDFs of the other reanalysis products (ERA-40, NCEP-1, and NCEP-2) in Fig. 2. Woollings et al. (2010a) report a value of -0.23 for the NAO computed from EOF analysis for 500-hPa geopotential height anomalies over the Atlantic. Similar values are found here; indeed, this value lies within the error bars for all indices. Note, 

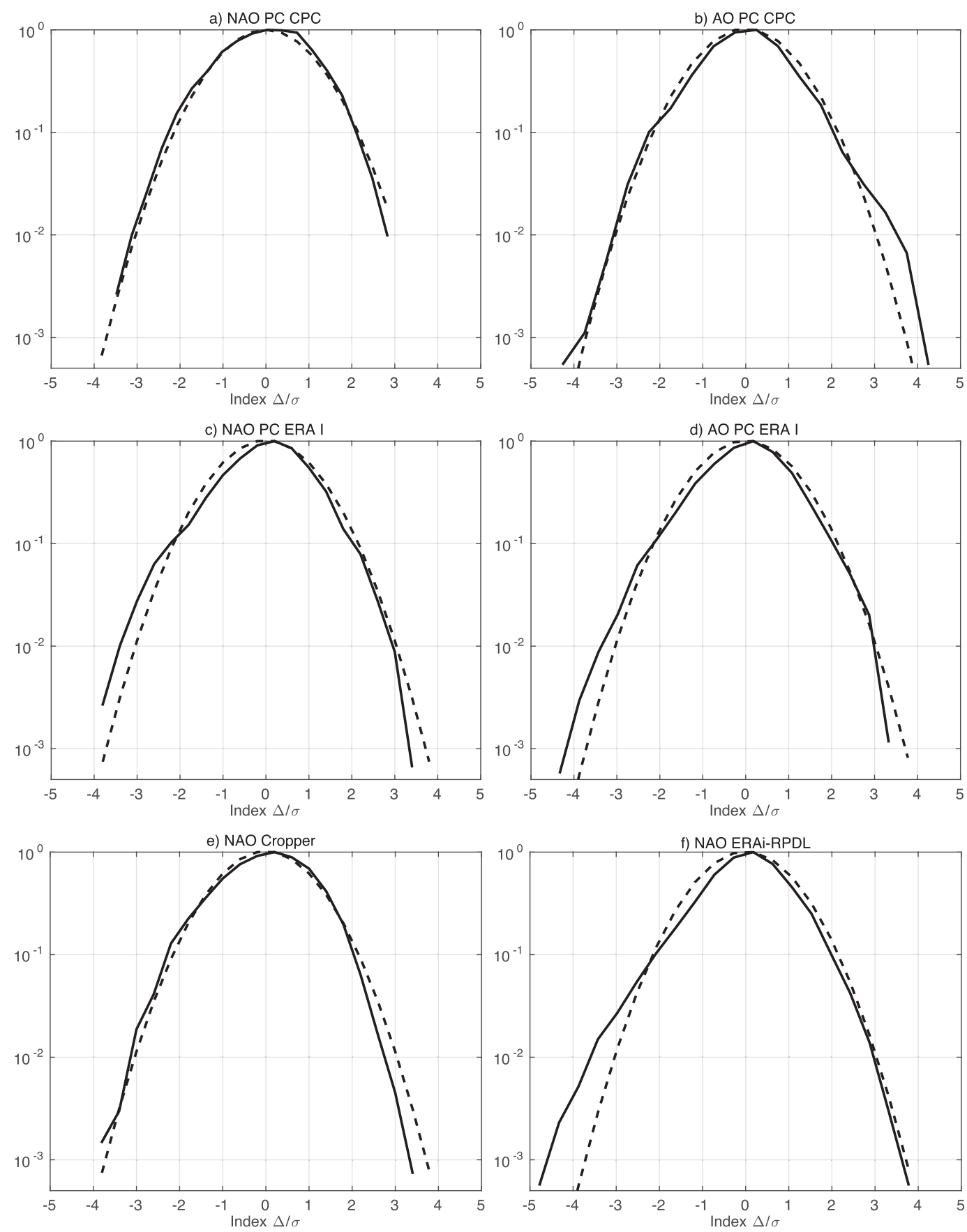

FIG. 2. PDFs for the index time series of the NAO and the AO normalized by their standard deviations: (a),(b) the CPC time series and (c),(d) ERA-Interim. (e),(f) The PDFs for the station-based NAO time series. The dashed line indicates a fitted normal distribution.

however, the small positive skewness of the AO PC from CPC, reminiscent of the smaller skewness reported in Woollings et al. (2010a) for using sea level pressure as compared to $500 \mathrm{hPa}$.

The standard error of skewness for a normal distribution [following Cramer (1998), Woollings et al. (2010a), and Sura and Hannachi (2015)] can for the sample size in this study be approximated as $\sqrt{6 / N}$, with $N$ the estimate of the number of independent samples in the time series, here evaluated through the characteristic time scale. Using $\tau_{E}$ and $\tau_{\mathrm{ZC}}$ for the characteristic time scale yields errors between 0.06 and 0.29 , 
respectively. The error values reported in Table 2 are based on $\tau_{\mathrm{ZC}}$ from Table 3 . The error margins indicate that the deviation of the skewness from zero is marginally greater than the standard error for most time series.

All proprietary time series (for both the $\mathrm{AO}$ and NAO) exhibit kurtosis values above 3 (Table 2), indicating weaker tails and more frequent values closer to the mean, while the Cropper et al. (2015) and CPC time series show a kurtosis slightly below Gaussian. Note, however, that the error bounds [here estimated as $\sqrt{24 / N}$ following Sura and Hannachi (2015) and Cramer (1998)] for the kurtosis are generally on the same order as the deviations from Gaussianity, especially for the NAO. The highest kurtosis values are observed for the proprietary station-based indices.

These results are consistent with the findings of Sura and Hannachi (2015, their Fig. 2), who find that midlatitude 500-hPa geopotential height generally exhibits a negative skewness, while positive skewness dominates the tropics and polar regions, especially for boreal winter (December-February). For the kurtosis, the small deviation from Gaussianity can be expected as the southern part of the North Atlantic and the North Pacific are dominated by positive kurtosis, while negative kurtosis values dominate farther north (Sura and Hannachi 2015).

To further evaluate the differences between the station-based and the EOF-based indices, the residuals from subtracting the NAO PC NCEP-2 time series from the Cropper et al. (2015) NAO time series are computed. The residuals exhibit a weakly negative skewness $(-0.09)$ and an almost Gaussian kurtosis (2.97), indicating that the shorter-term variability observed in the Cropper time series remains dominated by the negative sign of the NAO index, but to a much weaker extent, while the deviation from Gaussianity in the kurtosis of the PC-based indices has been removed.

The analysis shows that the state of the NAO has a tendency toward negative values, while strong positive values of the NAO pattern tend to occur less frequently. This can in part be explained by the experience that many teleconnection patterns are observed to project onto the negative phase of the NAO, such as El Niño (Brönnimann 2007). For La Niña, the projection onto the NAO is less clear (Butler and Polvani 2011), and it has been suggested that only strong La Niña events have a detectable impact on the stratosphere (Iza et al. 2016). It is also possible that other dominant weather patterns over the North Atlantic, as the ones described in Woollings et al. (2010b), project more dominantly onto the negative phase of the NAO. It has also been shown that the skewness of jet latitude, which is closely connected to the NAO, decreases with increasing jet latitude (Barnes and Hartmann 2010; Barnes and Polvani 2013; Hannachi et al. 2013).

For the winter season, Scaife et al. (2016) find that SSW events project onto higher absolute values of the (negative) NAO as compared to the positive values obtained for the NAO for strong polar vortex events. The hypothesis that stratospheric influence contributes to extreme NAO events is supported by the finding that the tails of the NAO distribution are more pronounced during boreal midwinter, when SSW and strong vortex events occur. When limiting the EOF-based NAO time series from ERA-Interim to December-February, the skewness reaches a value of -0.35 (as compared to -0.31 for the full year) and the kurtosis becomes negative $(-0.34)$, indicating heavier tails (i.e., more variability in the NAO index). When considering summer months only (JJA), the distribution is closer to Gaussian, with a negative skewness $(-0.31)$ and an almost Gaussian kurtosis $(+0.04)$ (not shown). Note that the strongest skewness is observed for the proprietary station-based ERAi-RPDL time series $(-0.36)$, that is, stronger than the Cropper et al. (2015) and ERAi-RPD time series that do not follow the seasonal movement of the NAO centers of action, indicating that tracking the centers that are most strongly linked to the winter NAO yields the stronger negative skewness. The notion that there may be enhanced predictability during winter as compared to summer can be confirmed in atmospheric general circulation model prediction studies; for example, Zuo et al. (2016) find that the predictability of the AO/NAO index is highest in boreal winter (December-March) and lowest in AugustNovember. The summer NAO has been less studied, although it has a significant connection to weather over Europe and the Mediterranean region (Folland et al. 2009; Bladé et al. 2012).

\section{c. Decorrelation time scales}

We here estimate the decorrelation behavior for the NAO and AO index time series. Table 3 shows the $\tau_{E}$ and $\tau_{\mathrm{ZC}}$. Figure 3 shows the first 60 days of the autocorrelation functions for the time series for the $\mathrm{AO}$ (top) and the NAO (bottom). The CPC time series has the longest decorrelation time of 9 (7) days for the AO (NAO), although all time series show a very similar and exponential decorrelation behavior within this time frame. For comparison, the dotted lines in Fig. 3 indicate an exponential decay of $e^{-t / \tau}$, where $\tau=3$ and 10 days. The standard error for the autocorrelation is estimated for ERA-Interim following Box et al. (1994) and is on the order of 0.025 for 30 days for both the AO and the NAO and encompasses all the other proprietary time series. 
a) $\mathrm{AO}$
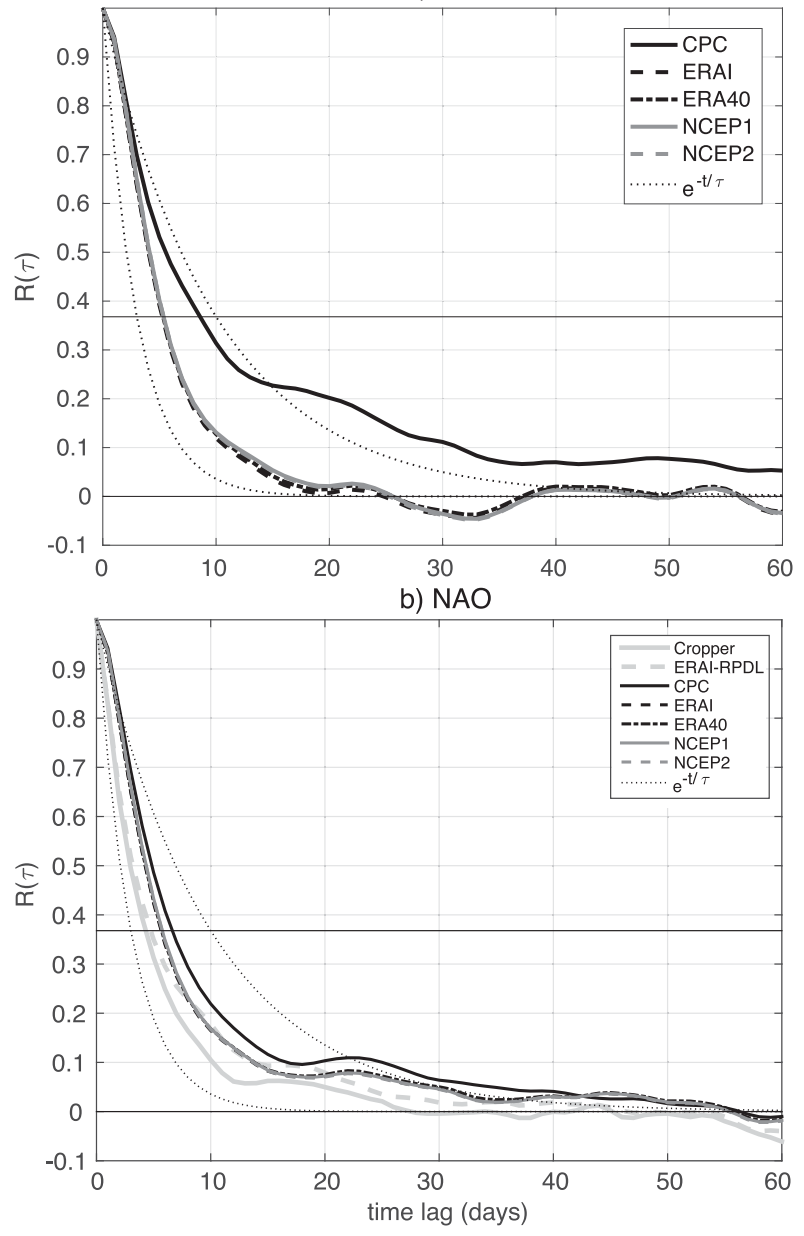

FIG. 3. Autocorrelation functions for (a) the AO and (b) the NAO. The horizontal lines indicate the values of $e^{-1}$ and zero. The dotted lines indicate the functions $e^{-t / \tau}$, where $\tau=3$ and 10 days.

For the AO CPC time series, the autocorrelation function reaches zero considerably later than for the other AO time series, while for the NAO CPC time series it is comparable to the other NAO time series. The AO CPC time series therefore exhibits a considerably longer $\tau_{\mathrm{ZC}}$ : although the initial decay is close to exponential, the decay slows after about 12 days and reaches zero only after 121 days. This difference for the AO time series is possibly due to the different level at which the index was computed: the NAO was computed at $500 \mathrm{hPa}$ for all EOF-based time series, while the AO index was computed at $1000 \mathrm{hPa}$ for the CPC time series, but at $500 \mathrm{hPa}$ for all other time series. For the stationbased Cropper et al. (2015) NAO index, $\tau_{\mathrm{ZC}}$ is reached earlier than for the other time series (i.e., after 28 days), comparable to $\tau_{\mathrm{ZC}}$ for the proprietary AO time series. The proprietary station-based indices ERAi-RPD and ERAi-RPDL show an autocorrelation behavior and $\tau_{\mathrm{ZC}}$ a) $\mathrm{AO}$

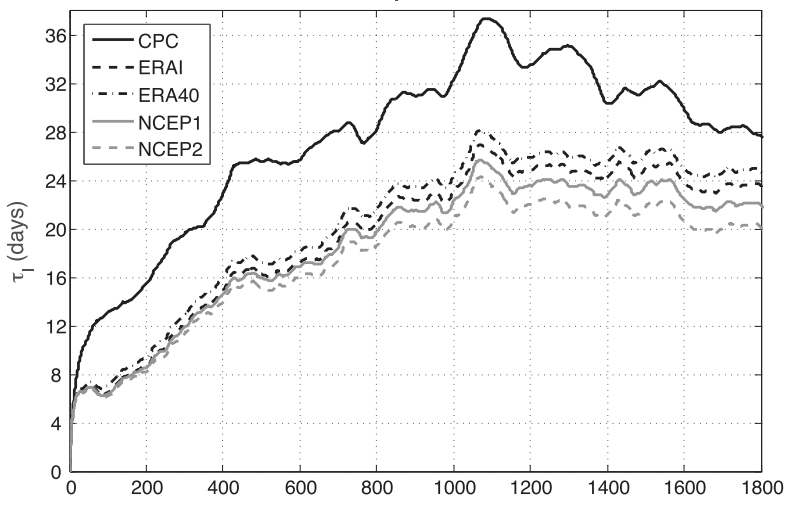

b) NAO

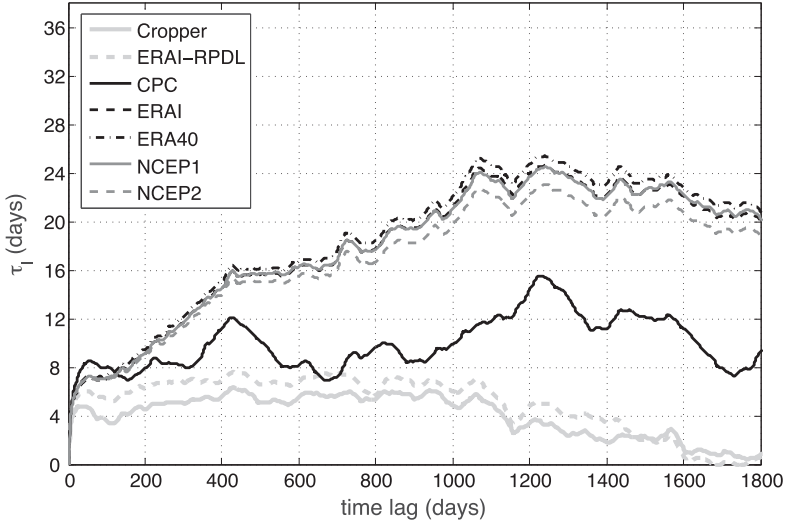

FIG. 4. The $\tau_{I}$ curves for (a) the AO and (b) the NAO.

values in between the EOF-derived indices and the Cropper index, but closer to the latter. Overall, $\tau_{\mathrm{ZC}}$ for the EOF-based NAO is considerably larger than for the $\mathrm{AO}$, with the exception of the surface AO time series.

Figure 4 shows the integrated decorrelation curves. The $\tau_{I}$ estimated from the curves are listed in Table 3. The proprietary EOF-based indices for the AO and NAO time series show a consistent behavior: the curves reach convergence after the first 30-60 days (i.e., on subseasonal-to-seasonal time scales) at a value of $\tau_{I} \sim$ 7 days, comparable to the time scales obtained for $\tau_{E}$. This corresponds to time scales of typical weather disturbance life cycles and to the predictability typically obtained in ensemble weather prediction models. After that, however, the integral curves begin to rise again and saturate after about 1100 days $(\sim 3 \mathrm{yr})$ at a value of $\tau_{I} \sim$ 20-25 (19-21) days for the AO (NAO). The emergence of two separate decorrelation time scales is reminiscent of Kunz and Greatbatch (2013), who found that the response of the NAM surface signal to stratospheric forcing results in two separate decay time scales of the signal: the quasigeostrophic adjustment mechanism (short time scales from a few days to weeks) and the 
tropospheric eddy feedback (time scales of several weeks). Keeley et al. (2009) also find that the persistence at time scales around 10-30 days is to a large degree due to external forcing.

The CPC indices behave differently. The AO CPC time series shows no initial convergence (i.e., no time scale is indicated in Table 3 ), reaches a maximum of 37 days after three years, and then decreases to a value of about 28 days. The NAO CPC time series integral time scale saturates after about 60 days to a value of about 8 days and then exhibits fluctuations of increasing amplitude for the remainder of the time period. The lack of the shorter time scale may be the result of the additional processing in the CPC calculation.

The NAO Cropper et al. (2015) time series as well as the proprietary station-based indices ERAi-RPD and ERAi-RPDL saturate quickly, in a month, to a small value of about 5-6 days, and after three years begin to decrease, suggestive of underlying long term variability. Possibly, the influence of the local processes or nonlinear variability and instrumental noise in the Cropper time series leads to a faster decorrelation. The consistent results for the ERAi-RPD and ERAi-RPDL support this conjecture.

\section{d. Power spectra}

Figure 5 shows the power spectra for the different $\mathrm{AO}$ and NAO time series. After the removal of the red part of the spectrum by detrending and deseasonalizing, the spectra become nearly flat at frequencies lower than semiannual, indicating that the remaining variability at these frequencies is an atmospheric white-noise-type variability. Note the higher power at the lowest resolved frequency $(\sim 10-20 \mathrm{yr})$ in the spectra of the EOFderived indices as compared to the station-based indices. This long-term component is not present in the station-based NAO indices, which may indicate a smaller contribution of oceanic variability, such as the Atlantic multidecadal oscillation (AMO; Kerr 2000) or solar teleconnections (Thiéblemont et al. 2015).

At higher frequencies, the spectra show a power-law decay as described in more detail below. For the AO, at subseasonal time scales (10-60 days), the spectra exhibit slopes approaching -1 (Fig. 5, dashed line). Slopes of -1 are characteristic for systems with long memory, which can be due to correlated point processes. Components of the climate system that exhibit -1 slopes include the Southern Hemisphere stratospheric polar vortex (Badin and Domeisen 2014b), sea surface temperature variability beyond one year (Fraedrich and Blender 2003), and the velocity fluctuations of sea ice (Gabrielski et al. 2015). These processes are often modeled as stochastic systems (Weissman 1988). For even shorter time scales, the spectra decay quickly to slopes close to -3 or steeper.

For the NAO time series, the EOF-derived indices yield similar results, also for the spectra; therefore, ERA-Interim is again chosen to represent ERA-40, NCEP-1, and NCEP-2. The NAO spectra tend to be steeper than the AO spectra at subseasonal time scales, with slopes approaching -2 (red noise). In comparison to the proprietary indices, the CPC spectra tend to decay faster at short time scales.

The faster decay of the NAO time series at subseasonal time scales as compared to the AO time series indicates an enhanced persistence of the extratropical Northern Hemisphere outside of the North Atlantic. Tropical influence may be a factor, where, for example, the ENSO influence is stronger in the North Pacific as compared to the North Atlantic. Analyzing the autocorrelation time scales for the PNA pattern, however, yields no significant difference in comparison to the NAO (not shown), indicating that the additional persistence may not arise from the North Pacific. Another possible contributor to enhanced persistence is the land surface over the large continents, for example, in terms of soil moisture (Hirschi et al. 2011; Orth and Seneviratne 2014) or snow cover (Cohen and Entekhabi 1999), which can influence the atmospheric circulation and predictability.

The slopes of -1 are suggestive of a somewhat higher predictability for the AO in comparison to the NAO, as a result of the correlations in the time series, which are responsible for the observed slopes. The transition from slope -1 to slope -3 that can be observed for the AO time series around time scales of about 10 days also tends to be typical of time series of the full longitudinal range for the Southern Hemisphere stratosphere (Badin and Domeisen 2014b), while the Northern Hemisphere stratosphere transitions to a steeper slope of -2 already at time scales of 100 days (Badin and Domeisen 2014a).

The station-based time series for the NAO again show a unique behavior: while all other time series show a decay with slope -2 for time scales down to 2 weeks, the spectra of the station-based indices at short time scales remain at a constant slope of -2 , indicating the contribution of the "noisy" short-scale variability that is filtered out when applying EOF analysis.

\section{e. Lyapunov spectra}

Finally, we quantify the predictability from the Lyapunov exponents. The Lyapunov spectra for the AO and NAO are shown in Fig. 6. The main results are summarized in Table 3. All index time series have two positive Lyapunov exponents, except for the stationbased NAO time series, which have only one. For the station-based NAO indices the Lyapunov spectrum 

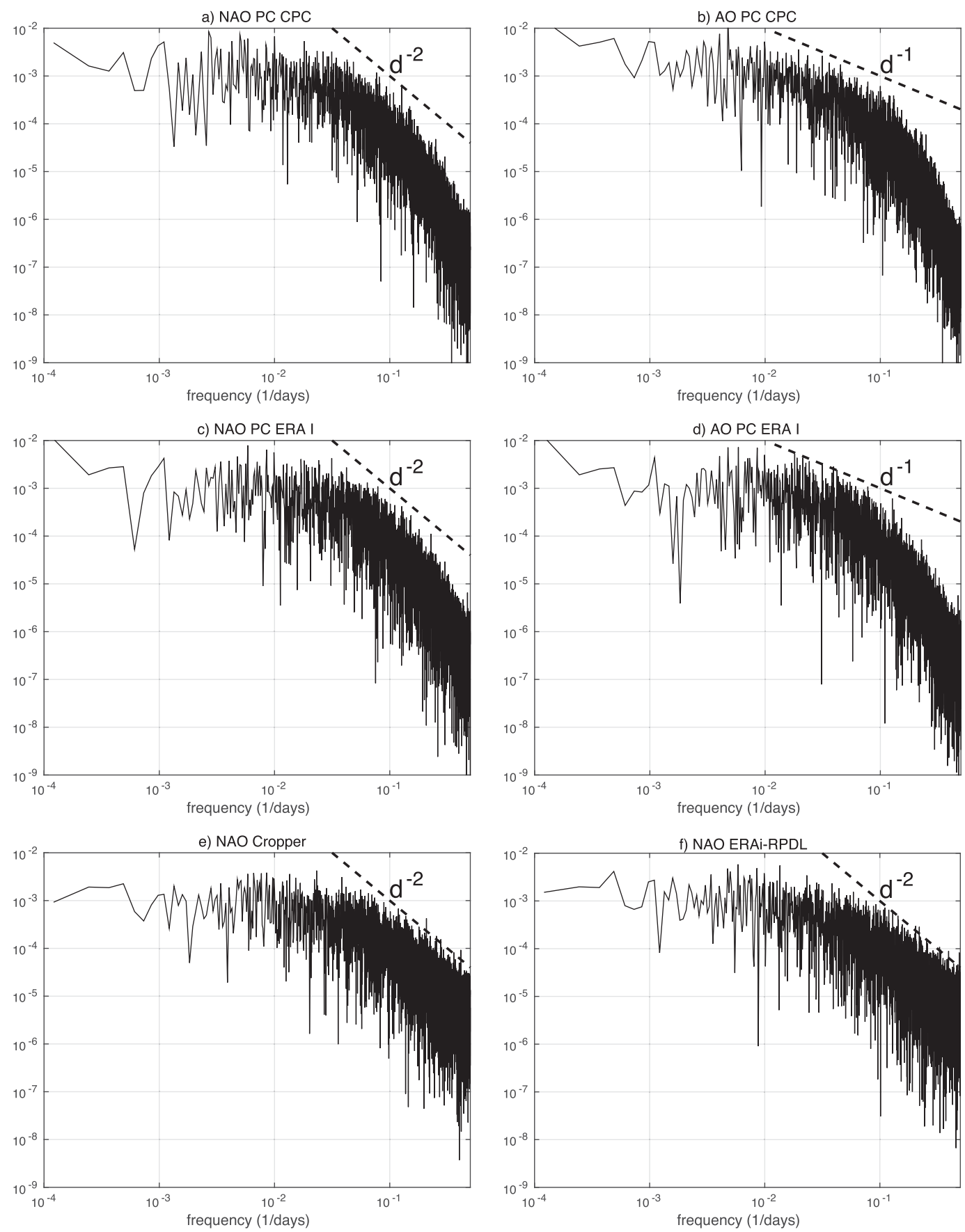

FIG. 5. As in Fig. 2, but for the power spectra. The dashed line indicates a slope following a power law of -1 for the $\mathrm{AO}$ and -2 for the NAO, as indicated.

decays faster than for the PC-based indices, which all exhibit very comparable Lyapunov spectra. All AO and NAO time series exhibit negative values for the sum of the Lyapunov exponents (Table 3, fourth column), in agreement with the dissipative nature of the system. The values for the EOF-based indices range from $-0.79 \pm 0.03 \mathrm{day}^{-1}$ for the NAO PC CPC time series to $-0.99 \pm 0.04 \mathrm{day}^{-1}$ for the NAO PC ERAInterim and ERA-40 time series. A very different behavior is once again found for the station-based NAO time series, which exhibit values for the sum of the Lyapunov exponents between -2.29 and -2.36 day $^{-1}$.

The characteristic time scale of predictability (computed from the inverse of the sum of all positive 
a) $\mathrm{AO}$

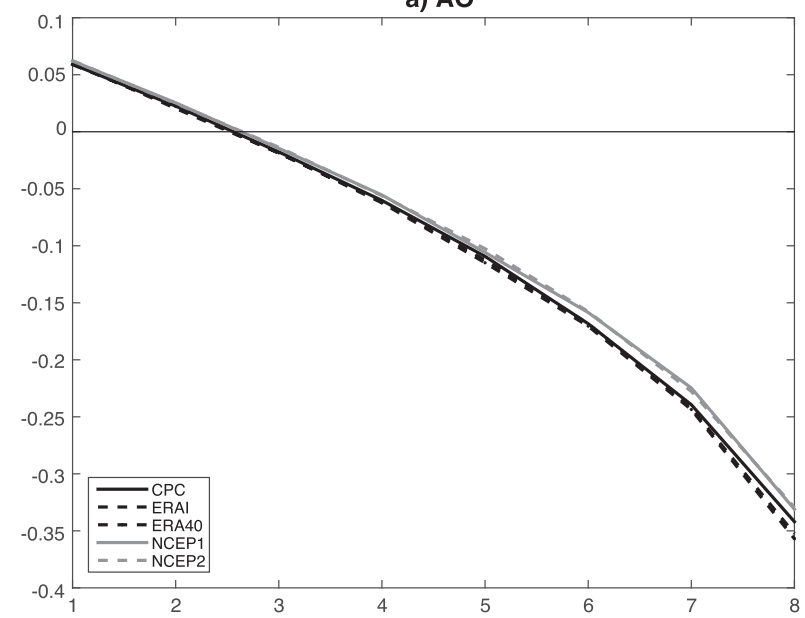

b) NAO

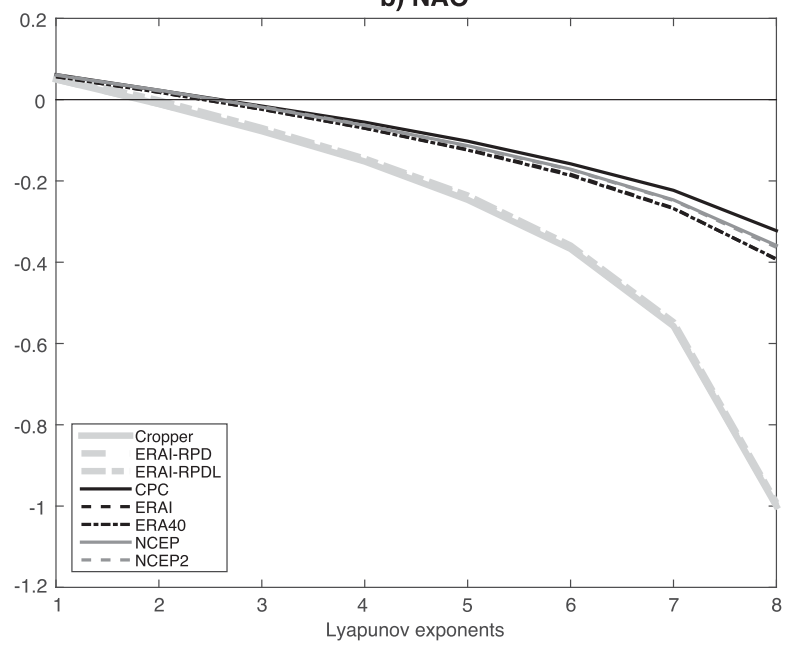

FIG. 6. Lyapunov spectra (i.e., the values of the Lyapunov exponents sorted by size as described in the text), for the index time series of (a) the AO and (b) the NAO. Note the different $y$ axes and the overlapping curves for the station-based indices.

Lyapunov exponents) is shown in Fig. 7 and listed in Table 3. For the AO, the time scale of predictability lies between 11 and 12 days. For the NAO, the predictability values are marginally longer, yielding time scales of 12-13 days. The error bars for both the AO and the NAO tend to be largest for ERA-40. The only time series that stand out are again the station-based NAO time series, which have a longer predictability time scale of 18-20 days. Note that the values for the station-based time series lie outside of the error margin of the EOFbased time series, while the error margins of the EOFbased time series encompass each other.

Table 3 also reports, for comparison, the characteristic time scale for predictability computed from the largest Lyapunov exponent only. The predictability time scales are extended by approximately $4-5$ days in comparison
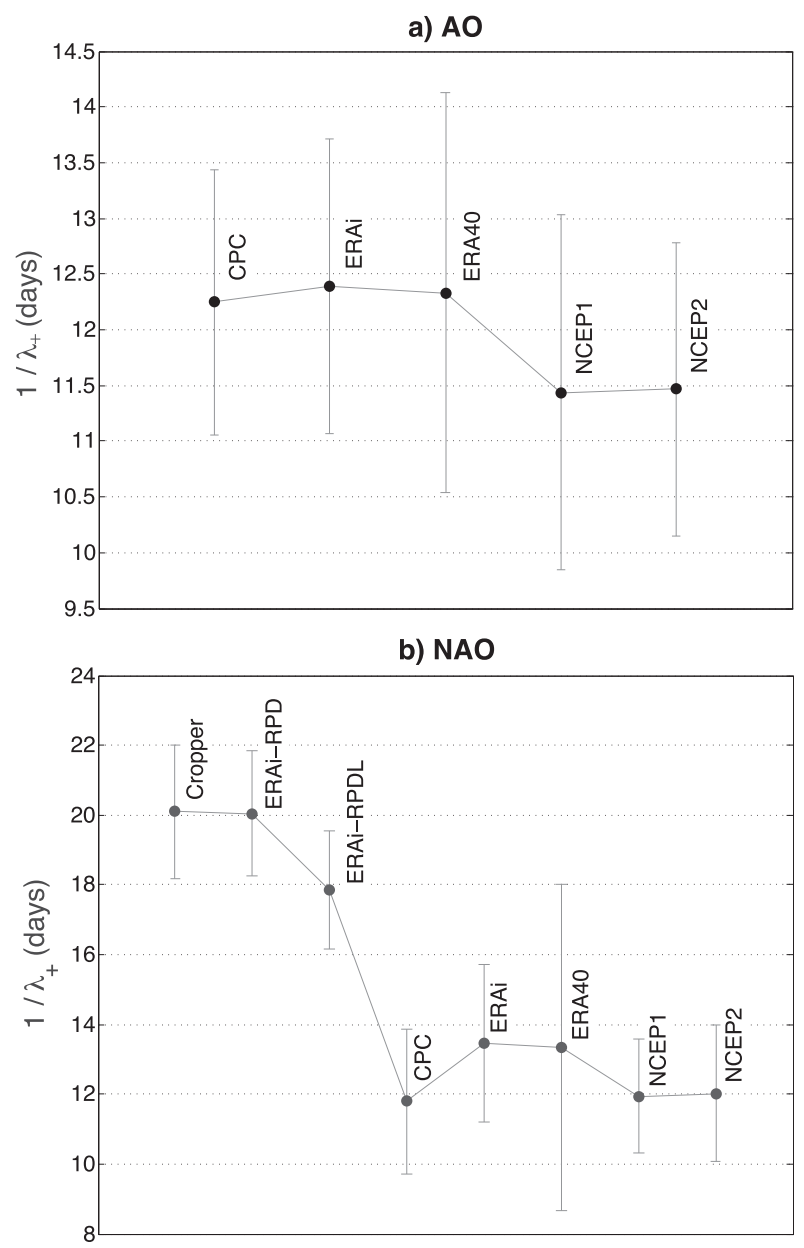

FIG. 7. The inverse of the sum of all positive Lyapunov exponents as a measure of predictability (days) for (a) the AO and (b) the NAO. Note the different $y$ axes. The error bars indicate the standard deviations for a sensitivity analysis with respect to the delay time, refer to section 3 for more details.

to the time scales computed from the sum of the positive Lyapunov exponents. In more detail, for the AO, the values range from around 16 days for the NCEP-2 time series to around 17 days for ERA-40. For the NAO, the values range from around 16 days for the $\mathrm{CPC}$ and NCEP- 2 time series to around $\sim 18$ days for ERAInterim. The values for the station-based NAO time series are the same as for the sum of the positive Lyapunov exponents, since these time series only exhibit one positive exponent.

The estimated KY dimension defined by (2) is shown as the last column in Table 3. The values for the EOFbased AO and NAO are comparable for all time series, ranging from around 3.7 for the NAO PC ERA time series to around 4.17 for the AO PC NCEP-2 time series. The station-based NAO time series stand out also for this measure, with a lower value of 2.5-2.8. All values of 
$D_{\mathrm{KY}}$ fulfill $D_{\mathrm{KY}}<M$, ensuring full exploration of the phase space of the system and thus a correct characterization of the Lyapunov spectra.

\section{Summary and discussion}

In this study, we have assessed the variability and predictability of the North Atlantic Oscillation (NAO) and the Arctic Oscillation (AO). We use the longest common time period ( $23 \mathrm{yr}$ ) for the available daily indices and focus on the differences between the datasets and methods employed to generate the index time series. The proprietary NAO and AO index time series are defined as the first principal component of geopotential height anomalies at $500 \mathrm{hPa}$ from the ERA-40, ERAInterim, NCEP-1, and NCEP-2 reanalysis products. Their properties are then compared to the NAO and AO indices from the Climate Prediction Center (CPC) and several station-based NAO indices. We quantify the variability of the time series using probability density functions, correlations, and power spectra, and to assess predictability, we use Lyapunov exponents.

While the indices derived from EOF analysis have the advantage of predominantly representing the largescale variability, they are also subject to a high degree of processing in terms of linearization and smoothing. We suggest that the additional processing may lead to a decrease in the predictability time scales obtained from the Lyapunov analysis. The station-based indices, on the other hand, exhibit more high-frequency variability and a higher degree of predictability.

In more detail, we find that for the proprietary EOFbased indices the exponential decay scale of the autocorrelation and the integral time scale $\tau_{I}$ is about one week. There is, however, a second characteristic linear time scale indicated by the zero crossing of the autocorrelation function $\tau_{\mathrm{ZC}}(\sim 30$ days for the $\mathrm{AO}$ and $\sim 55$ days for the NAO) and the long-term maximum of the integral time scale (20-25 days for both indices). The emergence of a secondary time scale is especially evident in the autocorrelation function for the $\mathrm{CPC} \mathrm{AO}$ at $1000 \mathrm{hPa}$ : it decays exponentially up to time scales of around 12 days and then follows a slower decay. This surface behavior is reminiscent of the two time scales of the NAM response found in Kunz and Greatbatch (2013), indicating that the tropospheric eddy feedback may be responsible for the slower decay at weekly to monthly time scales (Song and Robinson 2004; Domeisen et al. 2013). Keeley et al. (2009) also find external forcing to contribute significantly to additional persistence at time scales of around one month. The persistence is suggested to arise as a response to the influence of teleconnections from the upper atmosphere, the tropics, and the ocean (see section 4). In addition, Gerber et al. (2008a, their Fig. 3) show that the deviation from the exponential decay for the NAM is more evident in winter. Given that the AO signal obtained in our analysis is likely dominated by the winter variability, this could explain the deviation from the exponential decay. The strong evidence of this signal at the surface as compared to the midtroposphere may arise through the surface intensification of the signal, which can be observed during stratospheric influence during winter (Baldwin and Dunkerton 1999; Kidston et al. 2015).

Notably, the station-based NAO time series exhibit the shortest decorrelation time scale of about 5-6 days and no second maximum of $\tau_{I}$. The faster decorrelation may be due to local atmospheric processes, nonlinearities, or instrumental noise.

We also find that all time series show a small deviation from Gaussianity, especially in terms of their negative skewness, while the deviation from Gaussianity in the kurtosis is less clear. The negative skewness confirms earlier results by Woollings et al. (2010a) and Sura and Hannachi (2015) and can likely again be attributed to external processes, which tend to project onto the negative signature and the tails of the NAO and AO distributions.

The non-Gaussian part of the behavior of the PDFs may be a signature of the nonstationarity or a nonlinearity of the underlying system. Wunsch (1999) investigated over 130 years of a station-based NAO index time series arguing that apparent nonstationarity (e.g., trends) can be an artifact of the weakly red nature of the underlying stochastic process.

The higher power at the lowest frequencies of the EOF-derived indices as compared to the station-based indices for long time scales can possibly be attributed to solar teleconnections (Thiéblemont et al. 2015) and Atlantic multidecadal variability (Kerr 2000), which can however not be fully resolved by the time series analyzed here.

In terms of the predictability measures used here, the differences between the AO and the NAO tend to be negligible. Both exhibit predictive time scales of around 12 days for using the positive Lyapunov exponents and time scales of around 17 days for using the largest Lyapunov exponent only. Likewise, using an EOF-based definition of the AO close to the surface $(1000 \mathrm{hPa})$ and at $500 \mathrm{hPa}$ does not change the result in terms of the predictability time scale. This is more surprising given the differences obtained for the decorrelation measures. This result again only differs for the station-based indices, yielding a predictability time scale of 18-20 days, which is outside of the error bars of the predictability time scales for the other examined indices. 
In summary, both the emergence of a secondary time scale and the deviations from Gaussianity confirm recent studies that have hinted at a variety of remote influences onto the NAO that could significantly extend the predictable lead times on subseasonal time scales, especially in winter. Although the recent focus has been on the NAO, this study suggests that the same is true for the AO. Note that remote influences from, for example, the stratosphere and the tropics as well as local feedbacks can alter or extend predictability for particular atmospheric conditions and that statistical longer-term predictability is not captured by the Lyapunov analysis method employed in this study.

One fundamental result of our work is that computing the NAO or AO index time series using different reanalysis products does not change any of the statistics significantly. This may be surprising given the differences in, for example, spatial resolution (nominal resolutions of $2.5^{\circ}$ and $0.75^{\circ}$ in latitude/longitude for the NCEP and ECMWF reanalysis families). As the NAO and $\mathrm{AO}$ are large-scale features, this can likely be explained by the smoothing over the small-scale differences in the data. On the other hand, the method of index retrieval tends to matter, as can be observed from comparing the proprietary EOF-based indices to the indices from CPC and the station-based indices.

The analysis of the proprietary station-based indices indicates that predictability is indeed influenced by the index retrieval, with station-based indices exhibiting higher predictability than EOF-based indices. However, the construction of a station-based index that appropriately spans the seasonal variability of the NAO centers of action is a more complex issue, as indicated by the (comparably basic) ERAi-RPDL index that uses different stations depending on the season. The search for the appropriate index opens up a range of questions and will have to be addressed in more detail in the future. Overall, however, it has become clear that even when using reanalysis data to construct an artificial stationbased index [as compared to the station-based Cropper et al. (2015) index], predictability remains higher than for EOF-based indices.

While the analysis of the Lyapunov spectra and the characteristic period associated with the inverse sum of the positive Lyapunov exponents gives hints about the predictability of the system, more comprehensive studies of the nonlinear character of the system will be needed. For example, the system under consideration could present nontrivial scaling in time [i.e., being multifractal rather than (mono)fractal]. In this case, the growth of fluctuations follows power laws rather than exponential laws, for which there are no characteristic time scales and which are characterized by an infinite number of exponents. Moreover, if the system is multifractal, it will allow for intermittency, which can be responsible for the loss of predictability (see, e.g., Badin and Domeisen 2016). Further, in a turbulent system the largest Lyapunov exponent is likely to be associated with small scales, and the error growth associated with this will saturate at small scales, posing a limit to the information than can be inferred from the Lyapunov spectra (see, e.g., Vallis 2006).

As one of the main results of this study, we can conclude that the method for computing the NAO/AO time series has a significantly greater impact on the general properties and predictability of a time series than the use of differing reanalysis products. Since the stratosphere has been suggested to exert significant contributions to NAO/AO variability, this finding may be relevant to S-RIP [Stratosphere-Troposphere Processes and Their Role in Climate (SPARC) Reanalysis Intercomparison Project]. A planned future study will compare the obtained time scales to NAO and AO indices from model intercomparisons.

Note that it is not straightforward to compare the predictive time scales obtained in this study to the measures that tend to be used for ensemble prediction (e.g., anomaly correlation coefficients). However, it is clear that predictability time scales of 16-20 days are beyond what is currently possible to reliably forecast with ensemble weather prediction systems (Kolstad et al.2015). This hints at the possibility that there may be more day-to-day predictability in the system than currently found in weather prediction models and that knowing the nature of the observed processes may significantly influence their predictability. This is consistent with Eade et al. (2014) and Scaife et al. (2014), who underline the presence of unexploited predictability due to the low signal-to-noise ratio in state-of-the-art weather prediction models as compared to observations.

Acknowledgments. ERA-40 and ERA-Interim data have been obtained from the ECMWF Data Server. NCEP reanalysis data were obtained from the ESRL Data Server. The Cropper et al. (2015) time series has been obtained online (http://zenodo.org/record/9979\#. VrPGi9ayNNY) on 23 January 2017. The CPC time series have been obtained from NOAA/NCEP (http:// www.cpc.ncep.noaa.gov/products/precip/CWlink/pna/ nao.shtml and http://www.cpc.ncep.noaa.gov/products/ precip/CWlink/daily_ao_index/ao.shtml). GB was partially funded by the following German Research Foundation research grants: TRR 181, DFG 1740, and DFG BA5068/8-1. DD was partially funded by the Swiss National Science Foundation through Grant PP00P2 170523. The authors thank the anonymous reviewers for comments that helped to improve the manuscript. 


\section{REFERENCES}

Ansell, T. J., and Coauthors, 2006: Daily mean sea level pressure reconstructions for the European-North Atlantic region for the period 1850-2003. J. Climate, 19, 2717-2742, https:// doi.org/10.1175/JCLI3775.1.

Badin, G., and D. I. V. Domeisen, 2014a: A search for chaotic behavior in Northern Hemisphere stratospheric variability. J. Atmos. Sci., 71, 1494-1507, https://doi.org/10.1175/JAS-D-13-0225.1.

$\longrightarrow$, and $-2014 \mathrm{~b}$ : A search for chaotic behavior in stratospheric variability: Comparison between the Northern and Southern Hemispheres. J. Atmos. Sci., 71, 4611-4620, https:// doi.org/10.1175/JAS-D-14-0049.1.

_ fractal detrended fluctuation analysis and singularity spectra. Proc. Roy. Soc. London, 472A, 20150864, https://doi.org/ 10.1098/rspa.2015.0864.

- F. Crisciani, and G. Furlan, 2003: On the dynamics of quasigeostrophic intergyre gyres. Nuovo Cimento, 26, 621-632, https://doi.org/10.1393/ncc/i2003-10004-x.

Baldwin, M. P., and T. J. Dunkerton, 1999: Propagation of the Arctic Oscillation from the stratosphere to the troposphere. J. Geophys. Res., 104, 30 937-30 946, https://doi.org/10.1029/ 1999JD900445.

— , and —, 2001: Stratospheric harbingers of anomalous weather regimes. Science, 294, 581-584, https://doi.org/ 10.1126/science. 1063315 .

— based on zonal-mean data. Quart. J. Roy. Meteor. Soc., 135, 1661-1672, https://doi.org/10.1002/qj.479.

—, D. B. Stephenson, D. W. J. Thompson, T. J. Dunkerton, A. J. Charlton, and A. O'Neill, 2003: Stratospheric memory and skill of extended-range weather forecasts. Science, 301, 636-640, https://doi.org/10.1126/science.1087143.

Barnes, E. A., and D. L. Hartmann, 2010: Dynamical feedbacks and the persistence of the NAO. J. Atmos. Sci., 67, 851-865, https://doi.org/10.1175/2009JAS3193.1.

— their variability, to increased greenhouse gases in the CMIP5 models. J. Climate, 26, 7117-7135, https://doi.org/10.1175/ JCLI-D-12-00536.1.

Barnston, A. G., and R. E. Livezey, 1987: Classification, seasonality and persistence of low-frequency atmospheric circulation patterns. Mon. Wea. Rev., 115, 1083-1126, https://doi.org/ 10.1175/1520-0493(1987)115<1083:CSAPOL > 2.0.CO;2.

Black, R. X., 2002: Stratospheric forcing of surface climate in the Arctic Oscillation. J. Climate, 15, 268-277, https://doi.org/ 10.1175/1520-0442(2002)015<0268:SFOSCI > 2.0.CO;2.

Bladé, I., B. Liebmann, D. Fortuny, and G. J. van Oldenborgh, 2012: Observed and simulated impacts of the summer NAO in Europe: Implications for projected drying in the Mediterranean region. Climate Dyn., 39, 709-727, https://doi.org/ 10.1007/s00382-011-1195-x.

Box, G. E. P., G. M. Jenkins, and G. C. Reinsel, 1994: Time Series Analysis: Forecasting and Control. 3rd ed. Prentice Hall, 598 pp.

Brönnimann, S., 2007: Impact of El Niño-Southern Oscillation on European climate. Rev. Geophys., 45, RG3003, https://doi.org/ 10.1029/2006RG000199.

Butler, A., and L. Polvani, 2011: El Niño, La Niña, and stratospheric sudden warmings: A reevaluation in light of the observational record. Geophys. Res. Lett., 38, L13807, https://doi.org/ 10.1029/2011GL048084.
_ and Coauthors, 2016: The climate-system historical forecast project: Do stratosphere-resolving models make better seasonal climate predictions in boreal winter? Quart. J. Roy. Meteor. Soc., 142, 1413-1427, https://doi.org/10.1002/qj.2743.

Cassou, C., 2008: Intraseasonal interaction between the MaddenJulian oscillation and the North Atlantic Oscillation. Nature, 455, 523-527, https://doi.org/10.1038/nature07286.

Cohen, J., and D. Entekhabi, 1999: Eurasian snow cover variability and Northern Hemisphere climate predictability. Geophys. Res. Lett., 26, 345-348, https://doi.org/10.1029/1998GL900321.

Compo, G. P., and Coauthors, 2011: The Twentieth Century Reanalysis Project. Quart. J. Roy. Meteor. Soc., 137, 1-28, https:// doi.org/10.1002/qj.776.

Cramer, D., 1998: Fundamental Statistics for Social Research. Routledge, $89 \mathrm{pp}$.

Cropper, T., E. Hanna, M. A. Valente, and T. Jónsson, 2015: A daily Azores-Iceland North Atlantic Oscillation index back to 1850. Geosci. Data J., 2, 12-24, https://doi.org/10.1002/gdj3.23.

Dee, D. P., and Coauthors, 2011: The ERA-Interim reanalysis: Configuration and performance of the data assimilation system. Quart. J. Roy. Meteor. Soc., 137, 553-597, https://doi.org/ 10.1002/qj.828.

Delworth, T. L., F. Zeng, L. Zhang, R. Zhang, G. A. Vecchi, and $\mathrm{X}$. Yang, 2017: The central role of ocean dynamics in connecting the North Atlantic Oscillation to the extratropical component of the Atlantic multidecadal oscillation. J. Climate, 30, 3789-3805, https://doi.org/10.1175/JCLI-D-16-0358.1.

Deser, C., J. E. Walsh, and M. S. Timlin, 2000: Arctic sea ice variability in the context of recent atmospheric circulation trends. J. Climate, 13, 617-633, https://doi.org/10.1175/ 1520-0442(2000)013<0617:ASIVIT > 2.0.CO;2.

DeWeaver, E., and S. Nigam, 2000: Zonal-eddy dynamics of the North Atlantic Oscillation. J. Climate, 13, 3893-3914, https:// doi.org/10.1175/1520-0442(2000)013<3893:ZEDOTN>2.0.CO;2.

Domeisen, D. I. V., L. Sun, and G. Chen, 2013: The role of synoptic eddies in the tropospheric response to stratospheric variability. Geophys. Res. Lett., 40, 4933-4937, http://doi.org/10.1002/ grl.50943.

— A. H. Butler, K. Fröhlich, M. Bittner, W. Müller, and J. Baehr, 2015: Seasonal predictability over Europe arising from El Niño and stratospheric variability in the MPI-ESM seasonal prediction system. J. Climate, 28, 256-271, https://doi. org/10.1175/JCLI-D-14-00207.1.

Dunstone, N., D. Smith, A. Scaife, L. Hermanson, R. Eade, N. Robinson, M. Andrews, and J. Knight, 2016: Skilful predictions of the winter North Atlantic Oscillation one year ahead. Nat. Geosci., 9, 809-814, https://doi.org/10.1038/ ngeo2824.

Eade, R., D. Smith, A. Scaife, E. Wallace, N. Dunstone, L. Hermanson, and N. Robinson, 2014: Do seasonal-todecadal climate predictions underestimate the predictability of the real world? Geophys. Res. Lett., 41, 5620-5628, https:// doi.org/10.1002/2014GL061146.

Eden, C., and T. Jung, 2001: North Atlantic interdecadal variability: Oceanic response to the North Atlantic Oscillation (18651997). J. Climate, 14, 676-691, https://doi.org/10.1175/ 1520-0442(2001)014<0676:NAIVOR >2.0.CO;2.

Folland, C. K., J. Knight, H. W. Linderholm, D. Fereday, S. Ineson, and J. W. Hurrell, 2009: The summer North Atlantic Oscillation: Past, present, and future. J. Climate, 22, 1082-1103, https://doi.org/10.1175/2008JCLI2459.1.

Fraedrich, K., and R. Blender, 2003: Scaling of atmosphere and ocean temperature correlations in observations and climate 
models. Phys. Rev. Lett., 90, 108501, https://doi.org/10.1103/ PhysRevLett.90.108501.

Fraser, A. M., and H. L. Swinney, 1986: Independent coordinates for strange attractors from mutual information. Phys. Rev., 33A, 1134-1140, https://doi.org/10.1103/PhysRevA.33.1134.

Gabrielski, A., G. Badin, and L. Kaleschke, 2015: Anomalous dispersion of sea ice in the Fram Strait region. J. Geophys. Res. Oceans, 120, 1809-1824, https://doi.org/10.1002/2014JC010359.

Gao, Y., and Coauthors, 2015: Arctic sea ice and Eurasian climate: A review. Adv. Atmos. Sci., 32, 92-114, https://doi.org/10.1007/ s00376-014-0009-6.

Garfinkel, C. I., J. J. Benedict, and E. D. Maloney, 2014: Impact of the MJO on the boreal winter extratropical circulation. Geophys. Res. Lett., 41, 6055-6062, https://doi.org/10.1002/2014GL061094.

Gastineau, G., and C. Frankignoul, 2015: Influence of the North Atlantic SST variability on the atmospheric circulation during the twentieth century. J. Climate, 28, 1396-1416, https:// doi.org/10.1175/JCLI-D-14-00424.1.

Gerber, E., L. M. Polvani, and D. Ancukiewicz, 2008a: Annular mode time scales in the Intergovernmental Panel on Climate Change Fourth Assessment Report models. Geophys. Res. Lett., 35, L22707, https://doi.org/10.1029/2008GL035712.

— , S. Voronin, and L. M. Polvani, 2008b: Testing the annular mode autocorrelation time scale in simple atmospheric general circulation models. Mon. Wea. Rev., 136, 1523-1536, https://doi.org/10.1175/2007MWR2211.1.

Greatbatch, R., 2000: The North Atlantic Oscillation. Stoch. Env. Res. Risk Assess., 14A, 213-242, https://doi.org/10.1007/ s004770000047.

Gulev, S., and M. Latif, 2015: The origins of a climate oscillation. Nature, 521, 428-429, https://doi.org/10.1038/521428a.

Hall, R. J., A. A. Scaife, E. Hanna, J. M. Jones, and R. Erdélyi, 2017: Simple statistical probabilistic forecasts of the winter NAO. Wea. Forecasting, 32, 1585-1601, https://doi.org/ 10.1175/WAF-D-16-0124.1.

Hannachi, A., E. A. Barnes, and T. Woollings, 2013: Behaviour of the winter North Atlantic eddy-driven jet stream in the CMIP3 integrations. Climate Dyn., 41, 995-1007, https:// doi.org/10.1007/s00382-012-1560-4.

Hirschi, M., and Coauthors, 2011: Observational evidence for soilmoisture impact on hot extremes in southeastern Europe. Nat. Geosci., 4, 17-21, https://doi.org/10.1038/ngeo1032.

Hurrell, J. W., 1995: Decadal trends in the North Atlantic Oscillation: Regional temperatures and precipitation. Science, $\mathbf{2 6 9}$, 676-679, https://doi.org/10.1126/science.269.5224.676.

— , Y. Kushnir, and M. Visbeck, 2001: The North Atlantic Oscillation. Science, 291, 603-605, https://doi.org/10.1126/ science. 1058761.

Iza, M., N. Calvo, and E. Manzini, 2016: The stratospheric pathway of La Niña. J. Climate, 29, 8899-8914, https://doi.org/10.1175/ JCLI-D-16-0230.1.

Jones, P. D., T. Jónsson, and D. Wheeler, 1997: Extension to the North Atlantic Oscillation using early instrumental pressure observations from Gibraltar and south-west Iceland. Int. J. Climatol., 17, 1433-1450, https://doi.org/10.1002/(SICI)1097-0088(19971115)17: 13<1433::AID-JOC203>3.0.CO;2-P.

Kalnay, E., and Coauthors, 1996: The NCEP/NCAR 40-Year Reanalysis Project. Bull. Amer. Meteor. Soc., 77, 437-470, https:// doi.org/10.1175/1520-0477(1996)077<0437:TNYRP>2.0.CO;2.

Kanamitsu, M., W. Ebisuzaki, J. Woollen, S.-K. Yang, J. J. Hnilo, M. Fiorino, and G. L. Potter, 2002: NCEP-DOE AMIP-II Reanalysis (R-2). Bull. Amer. Meteor. Soc., 83, 1631-1643, https://doi.org/10.1175/BAMS-83-11-1631.
Kaplan, J. L., and J. A. Yorke, 1979: Chaotic behavior of multidimensional difference equations. Functional Differential Equations and Approximations of Fixed Points, H.-O. Peitgen and H.-O. Walther, Eds., Lecture Notes in Mathematics, Vol. 730, Springer, 204-227.

Keeley, S. P. E., R. T. Sutton, and L. C. Shaffrey, 2009: Does the North Atlantic Oscillation show unusual persistence on intraseasonal timescales? Geophys. Res. Lett., 36, L22706, https://doi.org/10.1029/2009GL040367.

Kerr, R. A., 2000: A North Atlantic climate pacemaker for the centuries. Science, 288, 1984-1985, https://doi.org/10.1126/ science.288.5473.1984.

Kidston, J., A. A. Scaife, S. C. Hardiman, D. M. Mitchell, N. Butchart, M. P. Baldwin, and L. J. Gray, 2015: Stratospheric influence on tropospheric jet streams, storm tracks and surface weather. Nat. Geosci., 8, 433-440, https://doi.org/10.1038/ngeo2424.

Kolstad, E. W., S. P. Sobolowski, and A. A. Scaife, 2015: Intraseasonal persistence of European surface temperatures. J. Climate, 28, 5365-5374, https://doi.org/10.1175/JCLI-D-15-0053.1.

Krahmann, G., and M. Visbeck, 2003: Variability of the northern annular mode's signature in winter sea ice concentration. Polar Res., 22, 51-57, https://doi.org/10.3402/polar.v22i1.6443.

Kunz, T., and R. J. Greatbatch, 2013: On the northern annular mode surface signal associated with stratospheric variability. J. Atmos. Sci., 70, 2103-2118, https://doi.org/10.1175/JAS-D-12-0158.1.

Mecking, J. V., N. S. Keenlyside, and R. J. Greatbatch, 2015: Multiple timescales of stochastically forced North Atlantic Ocean variability: A model study. Ocean Dyn., 65, 1367-1381, https://doi.org/10.1007/s10236-015-0868-0.

Orth, R., and S. I. Seneviratne, 2014: Using soil moisture forecasts for sub-seasonal summer temperature predictions in Europe. Climate Dyn., 43, 3403-3418, https://doi.org/ 10.1007/s00382-014-2112-x.

Panchev, S., 2016: The Eulerian-Lagrangian time-scale transformation in the planetary wave model. Random Functions and Turbulence, S. Panchev, Ed., International Series of Monographs in Natural Philosophy, Vol. 32, Elsevier, 415-417.

Pesin, I., 1976: Characteristic Lyapunov indices and ergodic properties of smooth dynamical systems with invariant measure. Dokl. Akademii Nauk SSSR, 226, 774-777.

Petoukhov, V., and V. A. Semenov, 2010: A link between reduced Barents-Kara sea ice and cold winter extremes over northern continents. J. Geophys. Res., 115, D21111, https://doi.org/ 10.1029/2009JD013568.

Richter, J. H., C. Deser, and L. Sun, 2015: Effects of stratospheric variability on El Niño teleconnections. Environ. Res. Lett., 10, 124021, https://doi.org/10.1088/1748-9326/10/12/124021.

Rodwell, M. J., and C. K. Folland, 2002: Atlantic air-sea interaction and seasonal predictability. Quart. J. Roy. Meteor. Soc., 128, 1413-1443, https://doi.org/10.1002/qj.200212858302.

Ruelle, R., 1990: Deterministic chaos: The science and the fiction. Proc. Roy. Soc. London, 427A, 241-248, https://doi.org/ 10.1098/rspa.1990.0010.

Sano, M., and Y. Sawada, 1985: Measurement of the Lyapunov spectrum from a chaotic time series. Phys. Rev. Lett., 55, 10821085, https://doi.org/10.1103/PhysRevLett.55.1082.

Scaife, A. A., J. R. Knight, G. K. Vallis, and C. K. Folland, 2005: A stratospheric influence on the winter NAO and North Atlantic surface climate. Geophys. Res. Lett., 32, L18715, https:// doi.org/10.1029/2005GL023226.

, and Coauthors, 2014: Skillful long-range prediction of European and North American winters. Geophys. Res. Lett., 41, 2514-2519, https://doi.org/10.1002/2014GL059637. 
and Coauthors, 2016: Seasonal winter forecasts and the stratosphere. Atmos. Sci. Lett., 17, 51-56, https://doi.org/ 10.1002/asl.598.

Semenov, V. A. and M. Latif, 2015: Nonlinear winter atmospheric circulation response to Arctic sea ice concentration anomalies for different periods during 1966-2012. Environ. Res. Lett., 10, 054020, https://doi.org/10.1088/1748-9326/10/5/054020.

Song, Y., and W. A. Robinson, 2004: Dynamical mechanisms for stratospheric influences on the troposphere. J. Atmos. Sci., 61, 1711-1725, https://doi.org/10.1175/1520-0469(2004)061<1711: DMFSIO $>2.0 . \mathrm{CO} ; 2$.

Stockdale, T. N., F. Molteni, and L. Ferranti, 2015: Atmospheric initial conditions and the predictability of the Arctic Oscillation. Geophys. Res. Lett., 42, 1173-1179, https://doi.org/ 10.1002/2014GL062681.

Sun, L., C. Deser, and R. A. Tomas, 2015: Mechanisms of stratospheric and tropospheric circulation response to projected Arctic sea ice loss. J. Climate, 28, 7824-7845, https://doi.org/ 10.1175/JCLI-D-15-0169.1.

Sura, P., and A. Hannachi, 2015: Perspectives of non-Gaussianity in atmospheric synoptic and low-frequency variability. J. Climate, 28, 5091-5114, https://doi.org/10.1175/JCLI-D-14-00572.1.

Takens, F., 1981: Detecting strange attractors in turbulence. $D y$ namical Systems and Turbulence, D. Rand and L. Young, Eds., Springer, 366-381.

Thiéblemont, R., K. Matthes, N.-E. Omrani, K. Kodera, and F. Hansen, 2015: Solar forcing synchronizes decadal North Atlantic climate variability. Nat. Commun., 6, 8268, https:// doi.org/10.1038/ncomms9268.

Thompson, D., and J. Wallace, 1998: Observed linkages between Eurasian surface air temperature, the North Atlantic Oscillation, Arctic sea level pressure and the stratospheric polar vortex. Geophys. Res. Lett., 25, 1297-1300, https://doi.org/ 10.1029/98GL00950.

-, and - 2000: Annular modes in the extratropical circulation. Part I: Month-to-month variability. J. Climate, 13, 1000-1016, https://doi.org/10.1175/1520-0442(2000)013<1000: AMITEC $>2.0 . \mathrm{CO} ; 2$.
,-- , and G. C. Hegerl, 2000: Annular modes in the extratropical circulation. Part II: Trends. J. Climate, 13, 1018-1036, https:// doi.org/10.1175/1520-0442(2000)013<1018:AMITEC>2.0.CO;2.

Uppala, S. M., and Coauthors, 2005: The ERA-40 Re-Analysis. Quart. J. Roy. Meteor. Soc., 131, 2961-3012, https://doi.org/ 10.1256/qj.04.176.

Vallis, G. K., 2006: Atmospheric and Oceanic Fluid Dynamics. Cambridge University Press, 745 pp.

Visbeck, M., 2002: The ocean's role in Atlantic climate variability. Science, 297, 2223-2224, https://doi.org/10.1126/science.1074029.

— J. W. Hurrell, L. Polvani, and H. Cullen, 2001: The North Atlantic Oscillation: Past, present, and future. Proc. Natl. Acad. Sci. USA, 98, 12 876-12 877, https://doi.org/10.1073/ pnas.231391598.

Weissman, M., 1988: 1/f noise and other slow, nonexponential kinetics in condensed matter. Rev. Mod. Phys., 60, 537-572, https://doi.org/10.1103/RevModPhys.60.537.

Whitney, H., 1936: Differentiable manifolds. Ann. Math., 37, 645680, https://doi.org/10.2307/1968482.

Woollings, T., A. Hannachi, B. Hoskins, and A. Turner, 2010a: A regime view of the North Atlantic Oscillation and its response to anthropogenic forcing. J. Climate, 23, 1291-1307, https:// doi.org/10.1175/2009JCLI3087.1.

,,--- , and $-2010 \mathrm{~b}$ : Variability of the North Atlantic eddy-driven jet stream. Quart. J. Roy. Meteor. Soc., 136, 856868, https://doi.org/10.1002/qj.625.

, C. Franzke, D. L. R. Hodson, B. Dong, E. A. Barnes, C. C. Raible, and J. G. Pinto, 2015: Contrasting interannual and multidecadal NAO variability. Climate Dyn., 45, 539-556, https://doi.org/10.1007/s00382-014-2237-y.

Wunsch, C., 1999: The interpretation of short climate records, with comments on the North Atlantic and Southern Oscillations. Bull. Amer. Meteor. Soc., 80, 245-255, https://doi.org/10.1175/ 1520-0477(1999)080<0245:TIOSCR > 2.0.CO;2.

Zuo, J., H.-L. Ren, J. Wu, Y. Nie, and Q. Li, 2016: Subseasonal variability and predictability of the Arctic Oscillation/North Atlantic Oscillation in BCC_AGCM2.2. Dyn. Atmos. Oceans, 75, 33-45, https://doi.org/10.1016/j.dynatmoce.2016.05.002. 